\title{
Positive Coping as a Mediator of Mobile Health Intervention Effects on Quality of Life Among People Living With HIV: Secondary Analysis of the Randomized Controlled Trial Run4Love
}

Yu Zeng ${ }^{1,2}$, MB; Yan Guo ${ }^{1,3}$, PhD; Rainbow Tin Hung $\mathrm{Ho}^{4,5}$, PhD; Mengting Zhu ${ }^{6}$, MS; Chengbo Zeng ${ }^{7}$, MS; Aliza Monroe-Wise ${ }^{8}$, MD, MSc; Yiran Li ${ }^{1}$, MS; Jiaying Qiao ${ }^{9}$, MS; Hanxi Zhang ${ }^{10}$, MS; Weiping Cai ${ }^{11}$, MD; Linghua Li ${ }^{11}$, MD; Cong Liu ${ }^{11}$, MSN

\footnotetext{
${ }^{1}$ Department of Medical Statistic, School of Public Health, Sun Yat-sen University, Guangzhou, China

${ }^{2}$ Longgang Center for Disease Control and Prevention in Shenzhen, Shenzhen, China

${ }^{3}$ Department of Population and Quantitative Health Sciences, University of Massachusetts Chan Medical School, Worcester, MA, United States

${ }^{4}$ Department of Social Work \& Social Administration, The University of Hong Kong, Hong Kong, China

${ }^{5}$ Centre on Behavioral Health, The University of Hong Kong, Hong Kong, China

${ }^{6}$ The Jockey Club School of Public Health and Primary Care, Faculty of Medicine, The Chinese University of Hong Kong, Hong Kong, China

${ }^{7}$ Department of Global Health and Social Medicine, Harvard Medical School, Boston, MA, United States

${ }^{8}$ Department of Global Health, University of Washington, Seattle, WA, United States

${ }^{9}$ Shanghai Center for Disease Control and Prevention, Shanghai, China

${ }^{10}$ National Center of AIDS/Sexually Transmitted Disease Control and Prevention, Chinese Center for Disease Control and Prevention, Beijing, China

${ }^{11}$ Department of Infectious Diseases, Guangzhou Number Eight People's Hospital, Guangdong, China
}

\section{Corresponding Author:}

Yan Guo, $\mathrm{PhD}$

Department of Medical Statistic

School of Public Health

Sun Yat-sen University

Guangzhou

China

Phone: 8602087334202

Email: Yan.Guo1@umassmed.edu

\section{Abstract}

Background: The effectiveness of psychosocial interventions on quality of life (QOL) among people living with HIV has been validated, including mobile health (mHealth) interventions. However, it is unclear which components of such interventions account for these effects.

Objective: This study aims to examine positive coping as a potential mediator of the effects of an mHealth intervention on QOL among people living with HIV.

Methods: For this secondary analysis, we used data from an mHealth-based randomized controlled trial, Run4Love, which was conducted to improve QOL and mental health outcomes of people living with HIV. A total of 300 participants were randomly assigned to the intervention group to receive the adapted cognitive-behavioral stress management courses and regular physical activity promotion or the waitlist control group in a 1:1 ratio. Our analysis focused on positive coping and QOL, which were repeatedly measured at baseline and at 3-, 6-, and 9-month follow-ups. Latent growth curve models were constructed to explore the mediating role of positive coping in the effects of the mHealth intervention on QOL.

Results: Positive coping served as a mediator in the effect of the mHealth intervention on QOL for up to 9 months. The mHealth intervention had a significant and positive indirect effect on the slope of QOL via the slope of positive coping $(b=2.592 \times 1.620=4.198,95 \%$ CI $1.189-7.207, P=.006)$. The direct effect of the intervention was not significant $(b=0.552,95 \%$ CI -2.154 to $3.258, P=.69$ ) when controlling for the mediator. 
Conclusions: The longitudinal findings suggest that positive coping could be a crucial mediator of the mHealth intervention in enhancing QOL among people living with HIV. These findings underscore the importance of improving positive coping skills in mHealth interventions to improve QOL among people living with HIV.

(J Med Internet Res 2022;24(2):e25948) doi: 10.2196/25948

\section{KEYWORDS}

mediation effect; mobile health; quality of life; positive coping; HIV; randomized controlled trial

\section{Introduction}

\section{Background}

Substantial improvements to and increased coverage in antiretroviral therapy have resulted in extended life expectancy of people living with HIV, leading to over 1.25 million HIV seropositive survivors in China [1,2]. With improved survival, quality of life (QOL) during treatment has become increasingly important for people living with HIV [3]. Owing to HIV disease progression and treatment side effects, the QOL of people living with HIV continues to be lower than that of people living with other chronic diseases, as well as the general population $[4,5]$. Poor QOL is not only related to suboptimal adherence to antiretroviral therapy, leading to inferior therapeutic effects [6], but is also associated with elevated HIV risk behavior, leading to increased risk of HIV transmission in the community [7]. Therefore, effective interventions to improve QOL in people living with HIV are warranted, especially those that can reach a large number of the targeted population, such as mobile health (mHealth) programs.

The literature suggests that psychosocial interventions such as cognitive-behavioral stress management (CBSM) programs can improve QOL in a variety of populations with chronic diseases, including people living with HIV [8-12]. Evidence also shows that mHealth-based psychosocial interventions produce similar benefits in comparison with face-to-face interventions, and they have additional advantages because of the easy accessibility and cost-effectiveness [13,14]. Nevertheless, the potential mechanism by which these mHealth interventions improve QOL among people living with HIV remains unclear. There might be various factors that affect the outcomes of the intervention. Mediation constitutes a mechanism through which the independent variable affects the dependent variable of interest [15]. Exploration of mediators will help understand the effective components of an intervention, which is crucial for future optimization of the program design [16].

A considerable amount of research has focused on exploring factors associated with QOL, with positive coping being one factor that has received substantial attention [17-21]. Positive coping is defined as individuals' active cognitive response (eg, trying to see the positive side) and adaptive behavioral response (eg, talking with family or friends) when managing stressful situations [22]. A substantial body of cross-sectional studies have shown that higher positive coping is related to higher QOL [18-20]. Some randomized controlled trials (RCTs) have indicated that positive coping might be a key determinant of the effectiveness of psychosocial interventions in improving QOL among people living with HIV [23,24]. For example, Hansen et al [24] found that HIV-positive participants reported significant postintervention improvement in both QOL and positive coping in the cognitive-behavioral support group, as well as in the control group providing mental health sessions and psychiatric services upon individual request. Using mixed models, the study also found that positive coping was directly associated with improved QOL in multiple time points across the intervention [24]. Similarly, another study revealed that a CBSM intervention was effective in improving positive coping in HIV-seropositive men who have sex with men, and positive coping might be an important predictor of QOL improvement [23].

Previous studies exploring the mediators of the effects of interventions on improving QOL have mostly been conducted in face-to-face settings $[23,25,26]$. It is unclear whether the factor mediating the effects of an intervention on QOL in face-to-face settings remains effective in mHealth settings. Furthermore, existing studies on mediation analysis mostly use pre- and postintervention data, whereas interventions in repeated measure design are lacking [11,23,25]. As 2-time point data contain limited information on individual changes, longitudinal data tracking over multiple time points $(\geq 3)$ may allow further investigation on the changes of both the mediator and the outcome, as well as the trajectory of the time-varying relationships between them over time [27].

\section{Objective}

To bridge the gaps in the existing literature, we used longitudinal data from the Run4Love study to examine the mediating role of positive coping on QOL in an mHealth intervention. The Run4Love study was a WeChat (Tencent)-based RCT to examine the intervention effects of an adapted CBSM course with physical activity promotion compared with usual care in people living with HIV. In this study, we hypothesized that the mHealth intervention would enhance the use of positive coping strategies in people living with HIV, which in turn was related to the significant improvement in QOL over time.

\section{Methods}

\section{Research Setting and Ethical Considerations}

The study used data from an mHealth-based RCT, Run4Love (ChiCTR-IPR-17012606) [28]. The Run4Love intervention was designed to improve mental health outcomes of people living with HIV, including, but not limited to, the reduction in depressive symptoms and improvement in QOL [28,29]. It was conducted from September 2017 to October 2018 in Guangzhou, the third-largest city of China [30]. A total of 300 participants were randomly assigned to either the intervention group to receive a 3-month WeChat-based mHealth program or the waitlist control group to receive usual care in a 1:1 ratio. The 
study design, recruitment procedures, and process of randomization were detailed in the study protocol, which was approved by the Institutional Review Board of Sun Yat-sen University [28].

\section{Participants Enrollment}

The trained research staff recruited participants from the infectious disease outpatient department of the only hospital designated for HIV care and treatment in Guangzhou. Patients who showed interest in the study were invited to participate in a consultation session to receive further information about the program and complete a screening questionnaire. Patients were eligible to participate if they met all of the following inclusion criteria: (1) aged $\geq 18$ years, (2) HIV seropositive, (3) having elevated depressive symptoms (Center for Epidemiologic Studies-Depression score $\geq 16$ ), and (4) using WeChat, the most popular instant messaging mobile program in China, with more than 1 billion active users worldwide [31]. Patients were excluded if they met any of the following exclusion criteria: (1) currently on psychotherapy or taking psychiatric drugs, (2) unable to complete the questionnaires, (3) unable to read or listen to the intervention materials, and (4) unable to engage in physical activities for medical reasons.

Participants who met the aforementioned eligibility criteria and provided written informed consent were enrolled in the study. Under the guidance of the research staff, participants were asked to complete electronic questionnaires in the outpatient department at baseline and 3-, 6-, and 9-month follow-ups. Participants would receive 50 RMB (ie, approximately US \$8) or gifts of equivalent value (eg, a yoga mat) as an incentive for completing each assessment.

\section{The Run4Love Intervention}

Participants in the intervention group received a 3-month WeChat-based intervention, which consisted of the adapted CBSM course and physical activity promotion [28]. CBSM is a therapeutic approach to teaching people living with HIV to manage their stress by focusing on how individuals' thoughts affect their emotions and behaviors and to influencing participants' irrational thoughts and changing their thought patterns and behaviors [32]. The adapted CBSM course mainly included coping and stress reduction skills such as meditation, muscle relaxation, and abdominal respiration training. The physical activity promotion program mainly included guidance on exercise, benefits of exercise, and a healthy diet. The content of these 2 intervention components was provided through 65 intervention materials in multiple formats, including short articles, motivational posters, and audio clips. These materials were delivered to participants on a near-daily basis (5-6 times a week) via an enhanced WeChat platform, the Run4Love platform. On average, each of the short articles had around 1300 words, which required about 5 minutes to read; each poster with motivational messages required about half a minute to read; each audio recording required 5 to 10 minutes to listen to [33].

Participants in the control group received a brochure on nutrition and healthy living style. They would be offered the Run4Love program as soon as the study was completed (ie, 9 months after their enrollment).

\section{Measurement}

\section{QOL Assessment}

QOL was measured using the 31-item World Health Organization Quality of Life HIV short version (WHOQOL-HIV BREF) at baseline and 3, 6, and 9 months. The WHOQOL-HIV BREF has been widely used among people living with HIV with proven reliability and validity $[34,35]$. The 31 -item scale measures QOL across six domains (ie, physical, psychological, level of independence, social relationships, environment, and spirituality) over the last 2 weeks. Each item was rated on a 5-point Likert scale ranging from 1 (not at all) to 5 (extremely), altogether providing a 4-20 score in each domain and a 24-120 score for the whole scale after the transformation, with higher scores indicating better QOL [34]. An example of these items assessing QOL was "How much do you enjoy life?" Good reliability of the WHOQOL-HIV BREF was shown in the study, and Cronbach $\alpha$ ranged from .727 to .838 across the 4 assessment points.

\section{Positive Coping}

Positive coping was measured using the 12-item subscale of the Simplified Ways of Coping Questionnaire with good reliability and validity in the Chinese populations [36-38]. The subscale consists of 12 items such as "Try to look on the bright side of things" and "Find out several different methods to solve the problem" to assess the frequency of positive attitudes and skills of coping that a participant adopted in daily life. Each item was rated on a 4-point Likert scale ranging from 0 (not use at all) to 3 (use frequently), providing a 0-36 score, with higher scores indicating higher levels of positive coping. Cronbach $\alpha$ ranged from .848 to .925 across the 4 assessment points in this study.

\section{Demographic Characteristics}

Demographic characteristics included age, gender, marital status, educational level, sexual orientation, employment status, family monthly income, and duration of HIV infection (years).

\section{Statistics Analysis}

The intention-to-treat principle was applied to all analyses in this study. Descriptive analyses of demographic characteristics, QOL, and positive coping were performed. Differences in outcome measures and baseline characteristics between the intervention and control groups were evaluated using the 2-tailed $t$ test or Wilcoxon rank-sum test for continuous variables and the chi-square test for categorical variables. Latent growth curve models (LGCMs) were constructed to examine the mediating role of positive coping in the effects of the mHealth intervention on QOL among people living with HIV. All statistical hypothesis tests were 2 -sided, and a $P$ value $<.05$ was considered statistically significant. Descriptive analyses and group comparisons of the key variables were conducted using $\mathrm{R}$ (version 3.5), and LGCMs were constructed using Mplus (version 7; Muthén \& Muthén). Missing data in all LGCMs were managed using the robust maximum likelihood estimation procedure.

The analyses of the mediation effect were conducted in 3 steps [39]. First, 2 unconditional LGCMs were constructed separately 
to estimate the growth trajectories of the outcome measure (QOL) and potential mediator variable (positive coping). The latent variables of intercept and slope (ie, the initial status and rate of change) were estimated from the repeated measures at 4 time points. For the intercept factor, the loadings across the 4 assessment points were fixed to 1 . For the slope factor, the first loading was fixed to 0 , the second to 1 , and the other loadings were freely estimated [40]. Instead of assuming a linear trajectory by setting the loadings onto the slope factor to 0,1 , 2 , and 3 , it was more reasonable to explore the potentially nonlinear trajectories by setting the third and fourth loadings free when the assumption of linear LGCM was unconfirmed [40].

Second, 2 conditional LGCMs were specified to separately examine the impact of the intervention on QOL and positive coping. The conditional models were extensions of the unconditional models to incorporate the variable of intervention group assignment (ie, intervention group $=1$ and control group=0) as a covariate.

Third, a parallel-process LGCM was constructed to evaluate whether the intervention was effective in improving QOL via the mediator variable of positive coping. The parallel-process model was a combination of the aforementioned 2 conditional LGCMs, which simultaneously estimated the trajectories of QOL and positive coping, and incorporated intervention group assignment as a covariate. The mediation effect was tested based on bias-corrected $95 \%$ bootstrapped CIs with a resampling of $5000[41,42]$.

Model fit was evaluated using chi-square test statistics and other indexes, including the Tucker-Lewis index (TLI), the comparative fit index (CFI), the root mean square error of approximation (RMSEA), and the standardized root mean square residual (SRMR). An LGCM with adequate model fit should meet the following criteria: TLI $>0.90, \mathrm{CFI}>0.90, \mathrm{RMSEA}<0.08$, and SRMR $<0.08$ [43-45].

\section{Results}

\section{Baseline Characteristics}

Descriptive statistics for baseline characteristics are shown in Table 1. The baseline characteristics of the participants were balanced between the intervention and control groups, except for the fact that a slightly higher proportion of heterosexual participants were allocated to the control group. The median age of the participants was 27.5 years, and the median duration of HIV infection was 1.7 years. The majority were male $(277 / 300,92.3 \%)$, well-educated $(182 / 300,60.7 \%$ with at least some college education), unmarried $(262 / 300,87.3 \%)$, and employed $(251 / 300,83.7 \%)$ and had a moderate level of income $(176 / 300,58.7 \%$ with family monthly income $<7000$ yuan [US $\$ 1100])$. Up to $81.7 \%$ (245/300) of the participants were homosexual, bisexual, or uncertain of their sexuality. 
Table 1. Baseline Characteristics of the participants in the Run4Love randomized controlled trial $(\mathrm{N}=300)$.

\begin{tabular}{|c|c|c|c|c|}
\hline Variables & Total $(\mathrm{N}=300)$ & Intervention $(\mathrm{n}=150)$ & Control $(n=150)$ & $P$ value \\
\hline Age (years), median (IQR) & $27.5(24.5-31.3)$ & $27.4(24.3-31.1)$ & $27.8(24.6-32.2)$ & .29 \\
\hline Gender, n (\%) & & & & .13 \\
\hline Male & $277(92.3)$ & $142(94.7)$ & $135(90)$ & \\
\hline Female & $23(7.7)$ & $8(5.3)$ & $15(10)$ & \\
\hline Educational level, n (\%) & & & & .10 \\
\hline$>$ High school & $182(60.7)$ & $98(65.3)$ & $84(65)$ & \\
\hline$\leq$ high school & $118(39.3)$ & $52(34.7)$ & $66(35)$ & \\
\hline Marital status, $\mathbf{n}(\%)$ & & & & .73 \\
\hline Single or divorced or widowed & $262(87.3)$ & $132(88)$ & $130(86.7)$ & \\
\hline Married & $38(12.7)$ & $18(12)$ & $20(85.3)$ & \\
\hline Employment status, $\mathbf{n}(\%)$ & & & & .29 \\
\hline Employed & $251(83.7)$ & $123(82)$ & $128(85.3)$ & \\
\hline Unemployed & $49(16.3)$ & $27(18)$ & $22(14.7)$ & \\
\hline Family monthly income (yuan), n (\%) & & & & .20 \\
\hline$\geq 7000$ (US \$1100) & $124(41.3)$ & $68(45.3)$ & $56(37.3)$ & \\
\hline$<7000$ (US \$1100) & $176(58.7)$ & $82(55.7)$ & $94(62.7)$ & \\
\hline Sexual orientation, $\mathrm{n}(\%)$ & & & & .03 \\
\hline Homosexual or bisexual or uncertain & $245(71.7)$ & $130(86.7)$ & $115(76.7)$ & \\
\hline Heterosexual & $55(18.3)$ & $20(13.3)$ & $35(23.3)$ & \\
\hline Duration of HIV infection (years), median (IQR) & $1.7(0.6-3.7)$ & $1.7(0.6-4.0)$ & $1.8(0.6-3.9)$ & .62 \\
\hline Positive coping, mean (SD) & $18.4(5.8)$ & $18.4(5.5)$ & $18.3(6.2)$ & .92 \\
\hline Quality of life, mean (SD) & $77.0(9.2)$ & $77.4(9)$ & $76.6(9.4)$ & .44 \\
\hline
\end{tabular}

\section{Changes in Repeated Measures}

Repeated measures of the outcome variable (ie, QOL) and potential mediator (ie, positive coping) at the 4 assessment points are presented in Table 2. The sample mean and 95\% CIs of QOL and positive coping over 9 months for both the intervention and control groups are presented in Figure 1. Participants in the intervention group had significantly higher levels of QOL and positive coping than those in the control group at the 3-, 6-, and 9-month follow-ups, indicating significant effects of the Run4Love mHealth intervention on improving QOL and positive coping over time. Specifically, in comparison with those in the control group, participants in the intervention group also had significantly higher mean scores in all 6 domains of QOL at the 3-, 6-, and 9-month follow-ups (Figure 2; Table 3).

Table 2. Repeated measures of quality of life and positive coping of the participants in the Run4Love randomized controlled trial.

\begin{tabular}{|c|c|c|c|c|c|c|}
\hline \multirow[t]{2}{*}{ Variables } & \multicolumn{3}{|c|}{ Quality of life, mean (SD) } & \multicolumn{3}{|c|}{ Positive coping, mean (SD) } \\
\hline & Intervention $^{\mathrm{a}}$ & Control $^{\mathrm{b}}$ & $P$ value & Intervention $^{\mathrm{a}}$ & Control $^{\mathrm{b}}$ & $P$ value \\
\hline Baseline & $77.43(9.03)$ & $76.59(9.42)$ & .44 & $18.39(5.46)$ & $18.32(6.15)$ & .92 \\
\hline 3 months & $82.54(12.03)$ & $76.63(11.08)$ & $<.001$ & $20.79(7.33)$ & $17.70(5.88)$ & $<.001$ \\
\hline 6 months & $83.51(12.88)$ & $76.32(12.96)$ & $<.001$ & $21.03(7.48)$ & $17.38(6.59)$ & $<.001$ \\
\hline 9 months & 83.48 (13.17) & $76.54(13.34)$ & $<.001$ & $20.95(7.75)$ & $18.31(6.41)$ & .003 \\
\hline
\end{tabular}

${ }^{\mathrm{a}}$ For variables in the intervention group, the sample sizes were 150, 139, 132, and 133 at baseline and 3-, 6-, and 9-month follow-ups, respectively.

${ }^{\mathrm{b}}$ For variables in the control group, the sample sizes were 150, 135, 133, and 127 at baseline and 3-, 6-, and 9-month follow-ups, respectively. 
Figure 1. Repeated measures of quality of life (QOL) and positive coping of the participants in the intervention and control groups over time. Error bars represent $95 \%$ CIs.
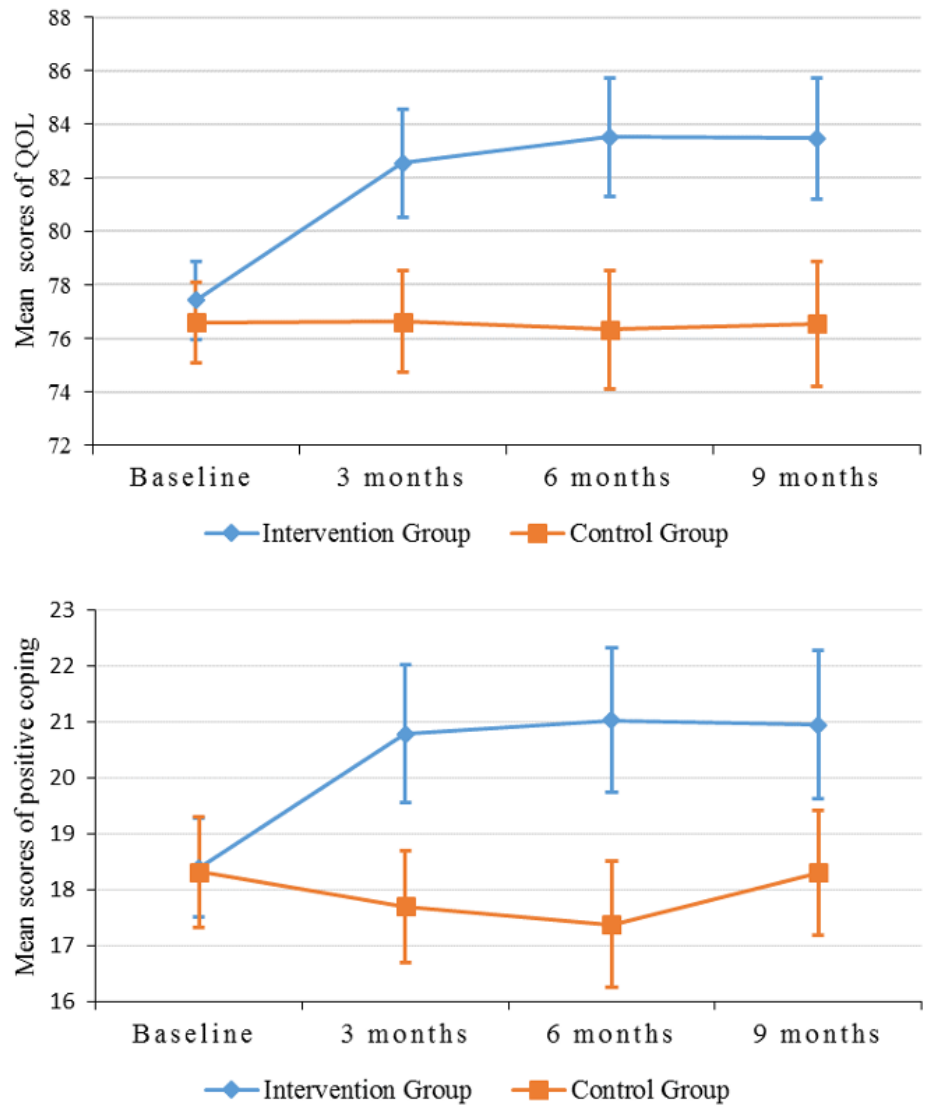

Figure 2. Repeated measures of the 6 domains in quality of life (QOL) of the participants in the intervention and control groups over time. Group 1 and Group 0 represent the intervention and control groups, respectively.

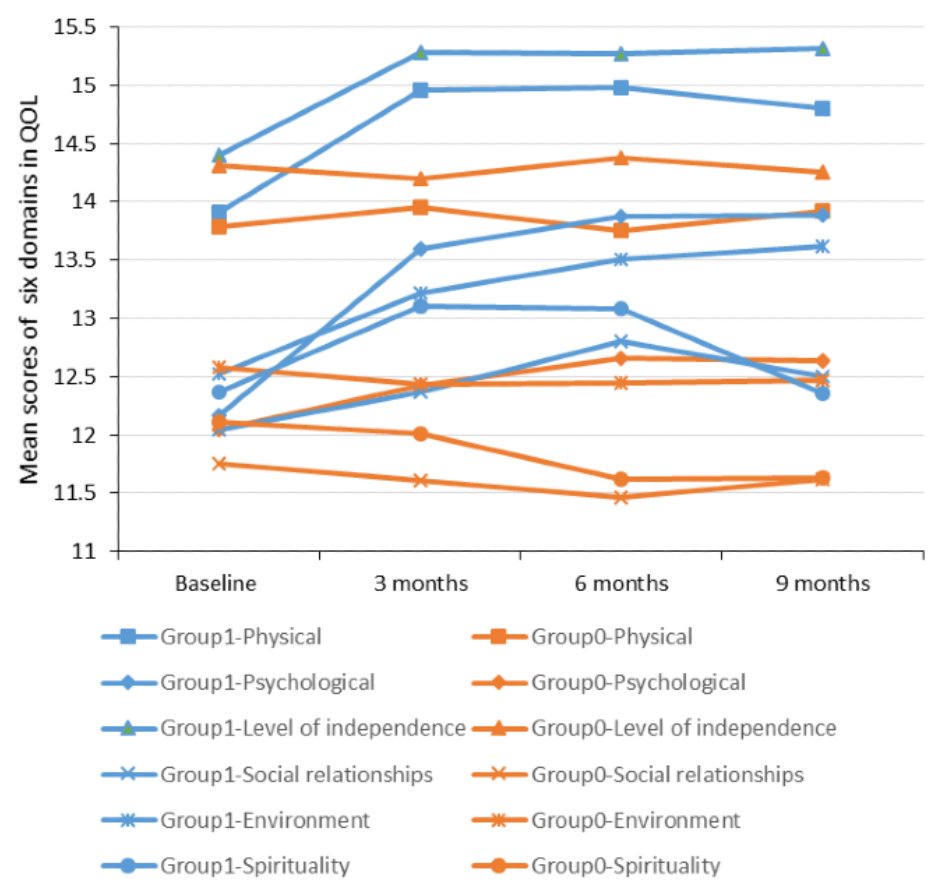


Table 3. Repeated measures of the 6 domains in quality of life of the participants in the Run4Love randomized controlled trial.

\begin{tabular}{|c|c|c|c|}
\hline Domains in quality of life & Intervention $^{\mathrm{a}}$ & Control $^{\mathrm{b}}$ & $P$ value \\
\hline \multicolumn{4}{|l|}{ Physical } \\
\hline Baseline & $13.91(2.05)$ & $13.79(2.39)$ & .66 \\
\hline 3 months & $14.96(2.45)$ & $13.95(2.60)$ & .001 \\
\hline 6 months & $14.98(2.69)$ & $13.75(2.77)$ & $<.001$ \\
\hline 9 months & $14.80(2.84)$ & $13.92(3.00)$ & .02 \\
\hline \multicolumn{4}{|l|}{ Psychological } \\
\hline Baseline & $12.17(2.17)$ & $12.04(2.08)$ & .60 \\
\hline 3 months & $13.60(2.50)$ & $12.42(2.24)$ & $<.001$ \\
\hline 6 months & $13.88(2.54)$ & $12.66(2.73)$ & $<.001$ \\
\hline 9 months & $13.89(2.83)$ & $12.64(2.60)$ & $<.001$ \\
\hline \multicolumn{4}{|l|}{ Level of independence } \\
\hline Baseline & $14.40(1.81)$ & $14.31(2.10)$ & .70 \\
\hline 3 months & $15.28(2.04)$ & $14.20(2.27)$ & $<.001$ \\
\hline 6 months & $15.27(2.23)$ & $14.38(2.26)$ & .002 \\
\hline 9 months & $15.32(2.29)$ & $14.26(2.38)$ & $<.001$ \\
\hline \multicolumn{4}{|l|}{ Social relationships } \\
\hline Baseline & $12.05(2.13)$ & $11.75(2.10)$ & .22 \\
\hline 3 months & $12.37(2.70)$ & $11.61(2.22)$ & .01 \\
\hline 6 months & $12.80(2.54)$ & $11.46(2.62)$ & $<.001$ \\
\hline 9 months & $12.50(2.53)$ & $11.62(2.42)$ & .005 \\
\hline \multicolumn{4}{|l|}{ Environment } \\
\hline Baseline & $12.52(1.93)$ & $12.58(2.08)$ & .80 \\
\hline 3 months & $13.22(2.44)$ & $12.44(2.15)$ & .005 \\
\hline 6 months & $13.51(2.45)$ & $12.45(2.74)$ & .001 \\
\hline 9 months & $13.62(2.35)$ & $12.47(2.56)$ & $<.001$ \\
\hline \multicolumn{4}{|l|}{ Spirituality } \\
\hline Baseline & $12.37(3.00)$ & $12.11(3.22)$ & .47 \\
\hline 3 months & $13.11(3.16)$ & $12.01(3.29)$ & .005 \\
\hline 6 months & $13.08(3.37)$ & $11.62(3.36)$ & $<.001$ \\
\hline 9 months & $13.36(3.22)$ & $11.63(3.49)$ & $<.001$ \\
\hline
\end{tabular}

${ }^{\mathrm{a}}$ For variables in the intervention group, the sample sizes were 150, 139, 132, and 133 at baseline and 3-, 6-, and 9-month follow-ups, respectively. ${ }^{b}$ For variables in the control group, the sample sizes were 150, 135, 133, and 127 at baseline and 3-, 6-, and 9-month follow-ups, respectively.

The dropout rates were $8.7 \%(26 / 300 ; 11 / 150,7.3 \%$ in the intervention group; $15 / 150,10.0 \%$ in the control group), $11.7 \%$ (35/300; $18 / 150,12.0 \%$ in the intervention group; $17 / 150,11.3 \%$ in the control group), and $13.3 \%(40 / 300 ; 17 / 150,11.3 \%$ in the intervention group; $23 / 150,15.3 \%$ in the control group) at 3-, 6-, and 9-month follow-ups, respectively. The average completion rate of the 3-month Run4Love program among people in the intervention group was $50.8 \%$ (33/65) [33].

\section{Results of LGCMs}

The results of the unconditional LGCMs indicated that both QOL and positive coping improved across the course of the study, and the largest improvement occurred at the 3-month follow-up. The path diagrams of these 2 unconditional LGCMs are presented in Figure 3. The unconditional LGCM for QOL had a good model fit: $\chi_{3}{ }_{3}=2.7(P=.26), \mathrm{CFI}=0.999$, TLI=0.996, $\mathrm{SRMR}=0.044$, and RMSEA $=0.034$ (Figure 3 ). The mean intercept was $77.032(P<.001$, SE 0.527$)$, indicating a mean QOL score of 77.032 at baseline. The mean slope was 2.241 $(P<.001$, SE 0.503$)$, and the factor loadings on the slope were $0,1,1.383$, and 1.362 at baseline and 3,6 , and 9 months, respectively. These results reflected a nonlinear pattern of improvement in QOL: a rapid increase in QOL scores (2.241 points) occurred at 3 months, and then the magnitude of improvement flattened out. The variances of the intercept and 
the slope of QOL were $92.509(P=.001)$ and $54.013(P=.04)$, respectively, which indicated significant individual differences in the initial levels and rates of change in QOL over time. The covariance between the intercept and the slope of QOL was $-16.029(P=.48)$, implying that the rate of change in QOL was not associated with its initial levels. The unconditional LGCM for positive coping also had a good model fit: $\chi_{3}^{2}=1.6(P=.66)$, $\mathrm{CFI}=1.000, \mathrm{TLI}=1.000, \mathrm{SRMR}=0.025$, and RMSEA $<0.001$ (Figure 3$)$. The mean positive coping score was $18.373(P<.001$, $\mathrm{SE}=0.340)$ at baseline, and the mean slope was $0.699(P=.04$, $\mathrm{SE}=0.336$ ). Similarly, the results of the slope factor also reflected a nonlinear pattern of improvement in positive coping: a rapid increase in positive coping scores ( 0.699 points) occurred at 3 months, and then the magnitude of improvement flattened out. The variances of the intercept and the slope in positive coping were $21.571(P=.01)$ and $10.194(P=.21)$, respectively, indicating significant individual differences in the initial levels of positive coping but not in its rates of change. The rate of change in positive coping was also unrelated to its initial levels, with a covariance between the intercept and the slope of -2.664 $(P=.70)$.

The results of the conditional LGCMs indicated that the mHealth intervention had significantly positive effects on both QOL and positive coping across the course of the study. The path diagrams of these 2 conditional LGCMs are also presented in Figure 3. The conditional model for QOL fitted the data well: $\chi^{2}{ }_{5}=3.3$ $(P=.50), \quad$ CFI $=1.000, \quad$ TLI $=1.000, \quad \mathrm{SRMR}=0.041, \quad$ and RMSEA $<0.001$ (Figure 3). The intervention had a significant impact on the slope factor $(b=4.705, \mathrm{SE}=0.911, P<.001)$, indicating an improvement in QOL in the intervention group compared with the control group over time. Similarly, the conditional model for positive coping fitted the data well: $\chi^{2}{ }_{5}=5.7(P=.34), \mathrm{CFI}=0.997, \mathrm{TLI}=0.995, \mathrm{SRMR}=0.030$, and RMSEA $=0.022$ (Figure 3 ). There was a higher rate of change in positive coping in the intervention group $(b=2.495, \mathrm{SE}=0.826$, $P=.003$ ), indicating a larger improvement in positive coping in the intervention group.

Figure 3. Path diagrams of the unconditional latent growth curve models (LGCMs) for quality of life (QOL) and positive coping and the conditional LGCMs with intervention groups as a covariate. Observed variables are denoted by boxes. Latent variables are denoted by ovals. Unidirectional arrows indicate the effects of 1 variable on the other. Bidirectional arrows indicate the correlations. The nonsignificant paths are shown as dotted lines. Intervention is either the Run4Love intervention group or the waitlist control group. I: intercept; PC: positive coping; S: slope; 0: baseline; 3: 3-month follow-up; 6: 6-month follow-up; 9: 9-month follow-up.
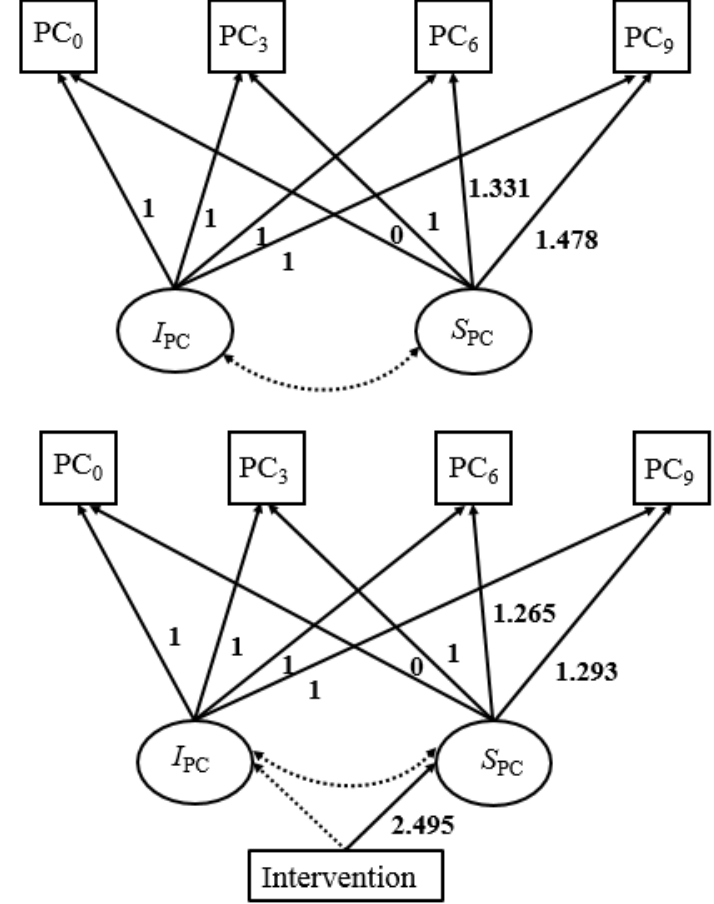

The results of the parallel process LGCM indicated that the mHealth intervention was effective in improving QOL via the mediation effect of positive coping. The path diagram of the parallel process LGCM is presented in Figure 4, and the estimates of the main coefficients are shown in Table 4. The results showed a good model fit for the parallel process LGCM: $\chi_{24}^{2}=64.1(P<.001), \mathrm{CFI}=0.971, \mathrm{TLI}=0.957, \mathrm{SRMR}=0.065$, and RMSEA $=0.075$ (Figure 4). The intervention had a significantly positive impact on the slope of positive coping $(b=2.592$, $P<.001)$, which in turn had a significantly positive impact on the slope of QOL $(b=1.620, \mathrm{SE}=0.321, P<.001)$. The indirect
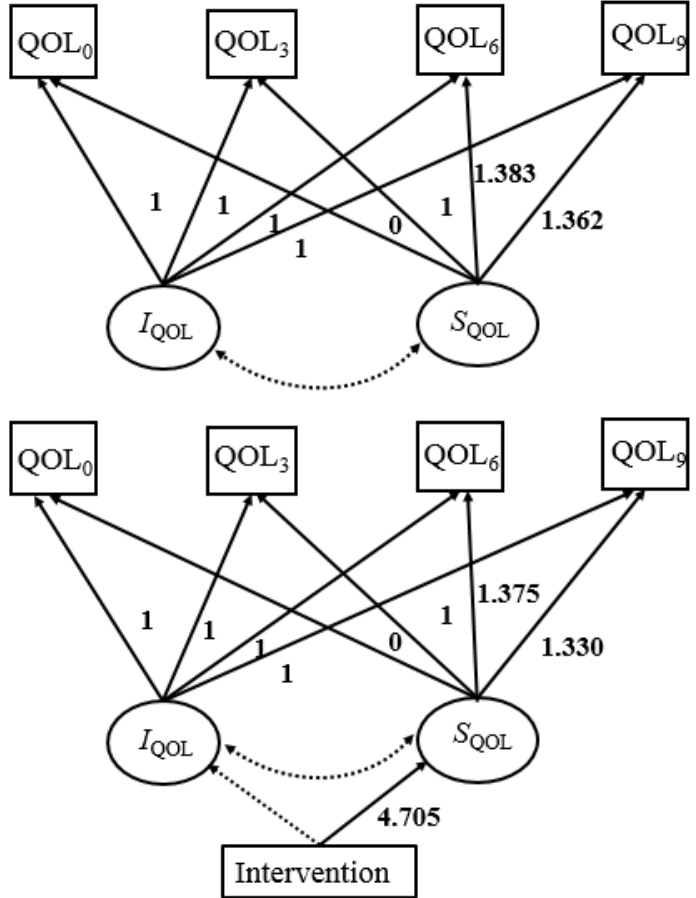

effect of the intervention on the slope of QOL via the slope of positive coping was significant $(b=2.592 \times 1.620=4.198, P=.006)$. These results indicated a mediation effect of positive coping on patients' QOL, where the exposure to the mHealth intervention significantly improved participants' positive coping over time, which in turn led to a positive change in QOL. The intervention no longer had direct effects on the slope of QOL $(b=0.552$, $P=$.69), indicating that the effects of the intervention on QOL might be explained by the mediation effect of positive coping. There were no significant differences as a function of intervention in the initial status of either repeated measures, 
indicating no group differences in the starting point for either positive coping or QOL. The covariance between the 2 intercepts was $21.571(P=.01)$, indicating that initial levels of positive coping were positively related to initial status with respect to QOL. In other words, participants who reported higher levels of positive coping at baseline tended to report higher levels of QOL at the same time. However, neither the covariance between the intercept of positive coping and the slope of QOL (2.941, $P=.26$ ) nor the covariance between the intercept of QOL and the slope of positive coping $(-3.900, P=.16)$ was statistically significant. These results indicated that the initial level of positive coping was not significantly associated with the rate of change in QOL, nor was the initial level of QOL and the rate of change in positive coping.

Figure 4. Path diagram of a parallel process latent growth curve model for quality of life (QOL) and positive coping with intervention groups as a covariate. Observed variables are denoted by boxes. Latent variables are denoted by ovals. Unidirectional arrows indicate the effects of 1 variable on the other. Bidirectional arrows indicate the correlations. The nonsignificant paths are shown as dotted lines. Intervention is either the Run4Love intervention group or the waitlist control group. I: intercept; PC: positive coping; S: slope; 0: baseline; 3: 3-month follow-up; 6: 6-month follow-up; 9: 9-month follow-up.

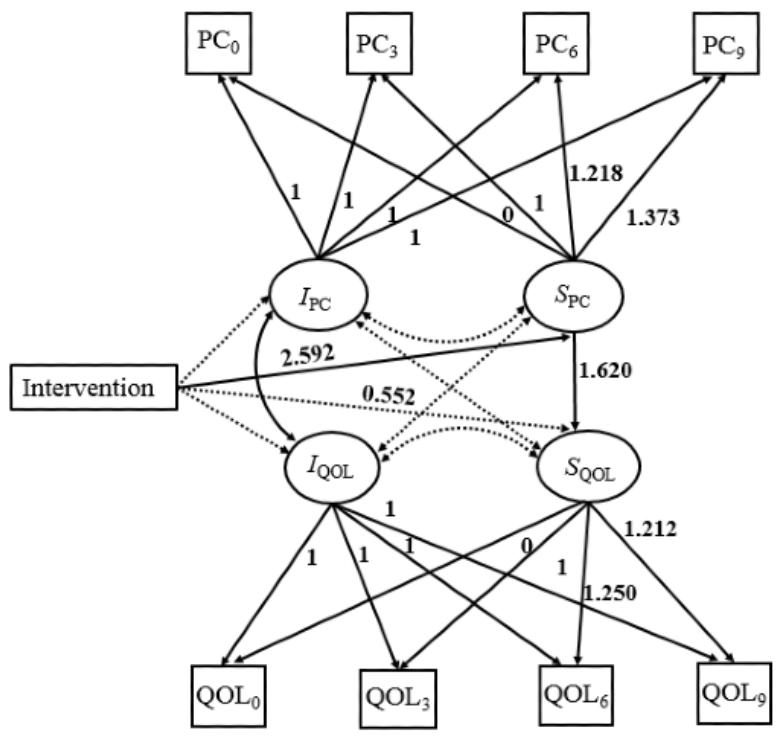

Table 4. Estimates of the coefficients in the parallel process latent growth curve model for quality of life and positive coping ( $\mathrm{n}=300)$.

\begin{tabular}{|c|c|c|c|c|c|}
\hline Coefficient & Estimate & $95 \% \mathrm{CI}$ & Standardized estimate & SE & $P$ value \\
\hline Intervention $\rightarrow \mathrm{QOL}^{\mathrm{a}}$ & 0.552 & -2.154 to 3.258 & 0.036 & 1.381 & .69 \\
\hline Intervention $\rightarrow$ positive coping & 2.592 & 1.124 to 4.060 & 0.398 & 0.749 & .001 \\
\hline Positive coping $\rightarrow$ QOL & 1.620 & 0.997 to 2.243 & 0.692 & 0.318 & $<.001$ \\
\hline Total effect & 4.750 & 2.766 to 6.734 & 0.311 & 1.012 & $<.001$ \\
\hline \multicolumn{6}{|l|}{ Direct effect } \\
\hline Intervention $\rightarrow \mathrm{QOL}$ & 0.552 & -2.154 to 3.258 & 0.036 & 1.381 & .69 \\
\hline \multicolumn{6}{|l|}{ Indirect effect } \\
\hline Intervention $\rightarrow$ positive coping $\rightarrow$ QOL & 4.198 & 1.189 to 7.207 & 0.275 & 1.535 & .006 \\
\hline
\end{tabular}

${ }^{\mathrm{a} Q O L}$ : quality of life.

\section{Discussion}

\section{Principal Findings}

To the best of our knowledge, our secondary analysis of data from the Run4Love study is among the first efforts to examine the mediating role of positive coping in patients' QOL in an mHealth-based RCT among people living with HIV. The results of LGCMs demonstrated that the Run4Love trial significantly improved positive coping among people living with HIV over 9 months, and the enhancement of positive coping led to significant improvement in QOL across the study. There was full mediation between positive coping and QOL in the Run4Love trial. Thus, our study revealed one of the potential mechanisms of improvement in QOL in mHealth-based CBSM interventions. To better design and implement effective interventions for people living with HIV, more studies are needed to investigate and identify the processes and/or mechanisms by which interventions lead to significant improvements in health outcomes, especially in emerging mHealth interventions [27].

Although several cross-sectional studies and 1 cohort study have examined the mediating role of positive coping on QOL 
[19-21], such designs are not sufficient for a robust conclusion because their findings are based on passive observational data. An experimental design in which the proper intervention is used to improve an individual's positive coping and QOL would greatly reduce confounding effects and enhance the strength of causal inferences. However, few RCTs have explored this relationship, especially in mHealth interventions. Only 1 face-to-face RCT showed that improvement in positive coping significantly mediated the effects of psychosocial intervention on QOL using pre- and postintervention assessments [25]. A comprehensive literature review suggested that mediation analysis could only be properly examined in well-designed RCTs with repeated measurements and sufficient power [27]. Thus, our study is well suited to investigate such a relationship and has confirmed the mediating role of positive coping on QOL, which may expand the literature on mechanisms of mHealth-based interventions.

In addition to the RCT design, the time point repeated measures and corresponding methodology of LGCM used in this study allow more conclusive findings and more abundant information for the mediation analysis or other research. Unlike cross-sectional data or pre- and postintervention data adopted in the previous literature, LGCMs that use longitudinal data allow the trajectory estimation of changes in outcome measures over time $[39,40]$. For example, the results of the LGCMs in our study suggested that both positive coping and QOL had increasing and nonlinear trajectories with a slower rate of increase over time, and there were statistically significant individual differences in the initial levels and rates of change of positive coping and QOL over time. In addition, the parallel process LGCM allowed for the examination of intercept-intercept, intercept-slope, and slope-slope relationships of the trajectories, which might extend our understanding of the relationships between the factors investigated [46]. In our study, we found a significant slope-slope relationship between positive coping and QOL, which indicated a mediation effect of positive coping on QOL in the mHealth intervention. Therefore, the LGCMs could not only estimate the growth curve of each outcome measure over time but also simultaneously examine the mediation relationship between 2 outcomes (eg, positive coping and QOL) in an intervention by controlling for their growth trajectories [39].

Given the critical role of positive coping in improving QOL, it is important to develop positive coping skills in mHealth interventions to improve participants' QOL. Previous psychosocial interventions for people living with HIV found that training in active cognitive and adaptive behavioral coping strategies was effective in improving positive coping $[23,47,48]$. In the Run4Love trial, we adapted the evidence-based CBSM intervention with important components of training in various types of coping skills, such as active cognitive coping (eg, mindfulness and problem- or emotion-oriented coping) and adaptive behavioral coping (eg, regular exercise) [28]. In addition, we adapted the CBSM courses originally designed for people living with HIV in the United States by removing some parts of the courses that were not suitable in the Chinese context, such as religion-related materials. Therefore, we had 9 sessions out of the original 10 sessions of the CBSM courses. Furthermore, as Chinese people living with HIV visit the hospital for antiretroviral drugs and regular clinical follow-ups every 3 months, we matched the patients' hospital visits and adapted the length of the intervention to 3 months by adding 3 review sessions and having weekly delivery of the total 12 sessions of the CBSM courses [28]. In addition, our CBSM intervention delivered in the mHealth platform allowed and encouraged participants' repeat visits to the training items, which might result in enhanced and sustained intervention effects over 9 months by repeatedly accessing the CBSM courses and practicing the coping skills, thus producing improved and sustained effects on patient outcomes such as QOL. To our knowledge, there is limited evidence about the long-term effects of mHealth interventions; few studies have reported intervention effects for over 6 months [49,50]. Few studies have been conducted on the potential mechanisms of the persistent intervention effects in mHealth interventions. The investigation in this study may provide important information and evidence on intervention mechanisms for long-term sustained effects in mHealth interventions.

\section{Limitations}

This study had several limitations. First, the self-reported data on positive coping and QOL in our study might have resulted in recall and social desirability biases. More objective measures, such as biomarkers, could be incorporated in future studies. Second, although participants were recruited from a large hospital for HIV treatment in Guangzhou with over 10,000 patients who were HIV seropositive, the sample was mostly from an urban setting and was predominantly male, particularly young men who have sex with men. Therefore, the generalizability of our findings should be treated with caution. Third, as all the 6 dimensions of QOL were improved in the intervention group at 3,6, and 9 months, and the improvement was not limited to the mental health dimension, it is possible that the improvement in QOL was also related to other factors besides positive coping, such as reduced depressive symptoms, stress, and/or HIV-related stigma and increased social support [51-53]. Although it is beyond the scope of this study to incorporate other factors, one of our previous studies found mediating roles of perceived stress and depressive symptoms for suicide reduction [53], whereas another study found positive coping and HIV-related stigma as intervention mediators on depressive symptoms [52]. Therefore, other potential mediators should be further explored to clarify the mechanisms of intervention effects and processes of how mHealth interventions improve health outcomes for better designing and implementing effective mHealth interventions.

\section{Conclusions}

In conclusion, this study found a full mediation effect of positive coping on QOL among people living with HIV in an mHealth intervention using 4 time point repeated measures and LGCMs. Future research and policies aimed at QOL improvement among people living with HIV should be designed with specific features that enhance the use of positive coping strategies. 


\section{Acknowledgments}

This study was supported by the National Natural Science Foundation of China (grant 71573290) and China Medical Board open competition funding (grant 17-271). The funding sources had no role in the study design, data collection, statistical analyses, or writing of the manuscript.

\section{Authors' Contributions}

YG and YZ had full access to all the data in the study and take responsibility for the integrity of the data and the accuracy of the data analysis. They contributed to the conceptualization and design of the study. YZ, MZ, CZ, YL, JQ, and HZ were responsible for the acquisition, analysis, or interpretation of data. YZ drafted the manuscript. YG, RH, AMW, and YZ conducted critical revision of the manuscript for important intellectual content. LL, WC, and CL provided administrative, technical, or material support. YG supervised the study.

\section{Conflicts of Interest}

None declared.

\section{References}

1. Nakagawa F, May M, Phillips A. Life expectancy living with HIV: recent estimates and future implications. Curr Opin Infect Dis 2013 Feb;26(1):17-25. [doi: 10.1097/QCO.0b013e32835ba6b1] [Medline: 23221765]

2. HIV/AIDS in China. Wikipedia. URL: https://en.wikipedia.org/wiki/HIV/AIDS in China [accessed 2020-08-23]

3. Cho H, Iribarren S, Schnall R. Technology-mediated interventions and quality of life for persons living with HIV/AIDS. A systematic review. Appl Clin Inform 2017 Dec 12;8(2):348-368. [doi: 10.4338/ACI-2016-10-R-0175] [Medline: 28401246]

4. Engelhard EA, Smit C, van Dijk PR, Kuijper TM, Wermeling PR, Weel AE, et al. Health-related quality of life of people with HIV: an assessment of patient related factors and comparison with other chronic diseases. AIDS 2018 Jan 02;32(1):103-112. [doi: 10.1097/QAD.0000000000001672] [Medline: 29112062]

5. Miners A, Phillips A, Kreif N, Rodger A, Speakman A, Fisher M, ASTRA (Antiretrovirals, Sexual Transmission and Attitudes) Study. Health-related quality-of-life of people with HIV in the era of combination antiretroviral treatment: a cross-sectional comparison with the general population. Lancet HIV 2014 Oct;1(1):32-40 [FREE Full text] [doi: 10.1016/S2352-3018(14)70018-9] [Medline: 26423814]

6. Penedo FJ, Gonzalez JS, Dahn JR, Antoni M, Malow R, Costa P, et al. Personality, quality of life and HAART adherence among men and women living with HIV/AIDS. J Psychosom Res 2003 Mar;54(3):271-278. [doi: 10.1016/s0022-3999(02)00482-8] [Medline: 12614837]

7. Zhu Y, Liu J, Qu B, Hu B, Zhang Y. Relationship between quality of life and unprotected anal intercourse among Chinese men who have sex with men: a cross-sectional study. BMC Public Health 2016 May 10;16:382 [FREE Full text] [doi: 10.1186/s12889-016-3076-z] [Medline: 27165001]

8. Stagl JM, Bouchard LC, Lechner SC, Blomberg BB, Gudenkauf LM, Jutagir DR, et al. Long-term psychological benefits of cognitive-behavioral stress management for women with breast cancer: 11-year follow-up of a randomized controlled trial. Cancer 2015 Jun 01;121(11):1873-1881 [ㅌREE Full text] [doi: 10.1002/cncr.29076] [Medline: 25809235]

9. Antoni MH, Lechner SC, Kazi A, Wimberly SR, Sifre T, Urcuyo KR, et al. How stress management improves quality of life after treatment for breast cancer. J Consult Clin Psychol 2006 Dec;74(6):1143-1152. [doi: 10.1037/0022-006X.74.6.1152] [Medline: 17154743 ]

10. Berger S, Schad T, von Wyl V, Ehlert U, Zellweger C, Furrer H, et al. Effects of cognitive behavioral stress management on HIV-1 RNA, CD4 cell counts and psychosocial parameters of HIV-infected persons. AIDS 2008 Mar 30;22(6):767-775. [doi: 10.1097/QAD.0b013e3282f511dc] [Medline: 18356607]

11. Penedo FJ, Molton I, Dahn JR, Shen B, Kinsinger D, Traeger L, et al. A randomized clinical trial of group-based cognitive-behavioral stress management in localized prostate cancer: development of stress management skills improves quality of life and benefit finding. Ann Behav Med 2006 Jun;31(3):261-270. [doi: 10.1207/s15324796abm3103 8] [Medline: 16700640]

12. Børøsund E, Ehlers SL, Varsi C, Clark MM, Andrykowski MA, Cvancarova M, et al. Results from a randomized controlled trial testing StressProffen; an application-based stress-management intervention for cancer survivors. Cancer Med 2020 Jun;9(11):3775-3785 [FREE Full text] [doi: 10.1002/cam4.3000] [Medline: 32243717]

13. Price M, Yuen EK, Goetter EM, Herbert JD, Forman EM, Acierno R, et al. mHealth: a mechanism to deliver more accessible, more effective mental health care. Clin Psychol Psychother 2014;21(5):427-436 [FREE Full text] [doi: 10.1002/cpp.1855] [Medline: 23918764]

14. Rathbone AL, Prescott J. The use of mobile apps and SMS messaging as physical and mental health interventions: systematic review. J Med Internet Res 2017 Aug 24;19(8):e295 [FRE Full text] [doi: 10.2196/jmir.7740] [Medline: 28838887]

15. Baron RM, Kenny DA. The moderator-mediator variable distinction in social psychological research: conceptual, strategic, and statistical considerations. J Pers Soc Psychol 1986 Dec;51(6):1173-1182. [Medline: 3806354] 
16. Kraemer HC, Wilson GT, Fairburn CG, Agras WS. Mediators and moderators of treatment effects in randomized clinical trials. Arch Gen Psychiatry 2002 Oct;59(10):877-883. [doi: 10.1001/archpsyc.59.10.877] [Medline: 12365874]

17. Leiberich P, Engeter M, Olbrich E, Rubbert A, Schumacher K, Brieger M, et al. Longitudinal development of distress, coping and quality of life in HIV-positive persons. Psychother Psychosom 1997;66(5):237-247. [doi: 10.1159/000289141] [Medline: 9311027$]$

18. Zhu M, Guo Y, Li Y, Zeng C, Qiao J, Xu Z, et al. HIV-related stigma and quality of life in people living with HIV and depressive symptoms: indirect effects of positive coping and perceived stress. AIDS Care 2020 Aug;32(8):1030-1035. [doi: 10.1080/09540121.2020.1752890] [Medline: 32290681]

19. Hernández-Ledesma AL, Rodríguez-Méndez AJ, Gallardo-Vidal LS, Trejo-Cruz G, García-Solís P, Dávila-Esquivel FD. Coping strategies and quality of life in Mexican multiple sclerosis patients: physical, psychological and social factors relationship. Mult Scler Relat Disord 2018 Oct;25:122-127. [doi: 10.1016/j.msard.2018.06.001] [Medline: 30071505]

20. Manne SL, Myers-Virtue S, Kashy D, Ozga M, Kissane D, Heckman C, et al. Resilience, positive coping, and quality of life among women newly diagnosed with gynecological cancers. Cancer Nurs 2015;38(5):375-382 [FREE Full text] [doi: 10.1097/NCC.0000000000000215] [Medline: 25521911]

21. Paek M, Ip EH, Levine B, Avis NE. Longitudinal reciprocal relationships between quality of life and coping strategies among women with breast cancer. Ann Behav Med 2016 Oct;50(5):775-783 [FREE Full text] [doi:

10.1007/s12160-016-9803-y] [Medline: 27272631]

22. Folkman S, Moskowitz JT. Coping: pitfalls and promise. Annu Rev Psychol 2004;55:745-774. [doi: 10.1146/annurev.psych.55.090902.141456] [Medline: 14744233]

23. Lutgendorf SK, Antoni MH, Ironson G, Starr K, Costello N, Zuckerman M, et al. Changes in cognitive coping skills and social support during cognitive behavioral stress management intervention and distress outcomes in symptomatic human immunodeficiency virus (HIV)-seropositive gay men. Psychosom Med 1998;60(2):204-214. [doi:

10.1097/00006842-199803000-00017] [Medline: 9560871]

24. Hansen NB, Tarakeshwar N, Ghebremichael M, Zhang H, Kochman A, Sikkema KJ. Longitudinal effects of coping on outcome in a randomized controlled trial of a group intervention for HIV-positive adults with AIDS-related bereavement. Death Stud 2006 Sep;30(7):609-636. [doi: 10.1080/07481180600776002] [Medline: 16865824]

25. Greer JA, Jacobs JM, El-Jawahri A, Nipp RD, Gallagher ER, Pirl WF, et al. Role of patient coping strategies in understanding the effects of early palliative care on quality of life and mood. J Clin Oncol 2018 Jan 01;36(1):53-60 [FREE Full text] [doi: 10.1200/JCO.2017.73.7221] [Medline: 29140772]

26. Gilts CD, Parker PA, Pettaway CA, Cohen L. Psychosocial moderators of presurgical stress management for men undergoing radical prostatectomy. Health Psychol 2013 Dec;32(12):1218-1226 [FREE Full text] [doi: 10.1037/a0030189] [Medline: 23088178]

27. Lemmens LH, Müller VN, Arntz A, Huibers MJ. Mechanisms of change in psychotherapy for depression: an empirical update and evaluation of research aimed at identifying psychological mediators. Clin Psychol Rev 2016 Dec;50:95-107. [doi: 10.1016/j.cpr.2016.09.004] [Medline: 27770716]

28. Guo Y, Hong YA, Qiao J, Xu Z, Zhang H, Zeng C, et al. Run4Love, a mHealth (WeChat-based) intervention to improve mental health of people living with HIV: a randomized controlled trial protocol. BMC Public Health 2018 Dec 26;18(1):793 [FREE Full text] [doi: 10.1186/s12889-018-5693-1] [Medline: 29940921]

29. Guo Y, Hong YA, Cai W, Li L, Hao Y, Qiao J, et al. Effect of a WeChat-based intervention (Run4Love) on depressive symptoms among people living with HIV in China: a randomized controlled trial. J Med Internet Res 2020 Feb 09;22(2):e16715 [FREE Full text] [doi: 10.2196/16715] [Medline: 32044751]

30. Guangzhou population 2020. World Population Review. URL: https://worldpopulationreview.com/world-cities/ guangzhou-population [accessed 2020-08-23]

31. WeChat. Wikipedia. URL: https://zh.wikipedia.org/wiki/\%E5\%BE\%AE\%E4\%BF\%A1 [accessed 2020-08-23]

32. Antoni M, Ironson G, Schneiderman N. Cognitive-Behavioral Stress Management for Individuals Living with HIV: Facilitator Guide. Oxford, UK: Oxford University Press; 2007.

33. Zeng Y, Guo Y, Li L, Hong YA, Li Y, Zhu M, et al. Relationship between patient engagement and depressive symptoms among people living with HIV in a mobile health intervention: secondary analysis of a randomized controlled trial. JMIR Mhealth Uhealth 2020 Oct 29;8(10):e20847 [FREE Full text] [doi: 10.2196/20847] [Medline: 33118956]

34. Hsiung P, Fang C, Wu C, Sheng W, Chen S, Wang J, et al. Validation of the WHOQOL-HIV BREF among HIV-infected patients in Taiwan. AIDS Care 2011 Aug;23(8):1035-1042. [doi: 10.1080/09540121.2010.543881] [Medline: 21500023]

35. Zhu Y, Liu J, Qu B. Psychometric properties of the Chinese version of the WHOQOL-HIV BREF to assess quality of life among people living with HIV/AIDS: a cross-sectional study. BMJ Open 2017 Aug 21;7(8):e016382 [FREE Full text] [doi: 10.1136/bmjopen-2017-016382] [Medline: 28827253]

36. Lei H, Cheong CM, Li S, Lu M. The relationship between coping style and internet addiction among mainland Chinese students: a meta-analysis. Psychiatry Res 2018 Dec;270:831-841. [doi: 10.1016/j.psychres.2018.10.079] [Medline: 30551332]

37. Cai Z, Li K, Zhang X. Workplace stressors and coping strategies among Chinese psychiatric nurses. Perspect Psychiatr Care 2008 Oct;44(4):223-231. [doi: 10.1111/j.1744-6163.2008.00181.x] [Medline: 18826460] 
38. Xie Y. Reliability and validity of the simplified Coping Style Questionnaire. Chinese J Clin Psychol 1998. [doi: 10.16128/j.cnki.1005-3611.1998.02.018]

39. Cheong J, Mackinnon DP, Khoo ST. Investigation of mediational processes using parallel process latent growth curve modeling. Struct Equ Model 2003 Apr 01;10(2):238 [FREE Full text] [doi: 10.1207/S15328007SEM1002_5] [Medline: 20157639]

40. Bollen KA, Curran PJ. Latent Curve Models: A Structural Equation Perspective. Hoboken, New Jersey, United States: John Wiley \& Sons Inc; 2005.

41. Zhao X, Lynch JG, Chen Q. Reconsidering Baron and Kenny: myths and truths about mediation analysis. J Consum Res 2010 Aug 01;37(2):197-206. [doi: 10.1086/651257]

42. Preacher KJ, Hayes AF. SPSS and SAS procedures for estimating indirect effects in simple mediation models. Behav Res Methods Instrum Comput 2004 Nov;36(4):717-731. [doi: 10.3758/bf03206553] [Medline: 15641418]

43. Hu L, Bentler PM. Cutoff criteria for fit indexes in covariance structure analysis: conventional criteria versus new alternatives. Struct Equat Model Multidiscipl J 1999 Jan;6(1):1-55. [doi: 10.1080/10705519909540118]

44. Bentler PM. Fit indexes, lagrange multipliers, constraint changes and incomplete data in structural models. Multivar Behav Res 1990 Apr 01;25(2):163-172. [doi: 10.1207/s15327906mbr2502 3] [Medline: 26794478]

45. Browne MW, Cudeck R. Alternative ways of assessing model fit. Sociol Methods Res 2016 Jun 29;21(2):230-258. [doi: 10.1177/0049124192021002005]

46. Muniz-Terrera G, Robitaille A, Kelly A, Johansson B, Hofer S, Piccinin A. Latent growth models matched to research questions to answer questions about dynamics of change in multiple processes. J Clin Epidemiol 2017 Feb;82:158-166 [FREE Full text] [doi: 10.1016/j.jclinepi.2016.09.001] [Medline: 27639542]

47. Chesney MA, Chambers DB, Taylor JM, Johnson LM, Folkman S. Coping effectiveness training for men living with HIV: results from a randomized clinical trial testing a group-based intervention. Psychosom Med 2003;65(6):1038-1046. [doi: 10.1097/01.psy.0000097344.78697.ed] [Medline: 14645783]

48. Fife BL, Scott LL, Fineberg NS, Zwickl BE. Promoting adaptive coping by persons with HIV disease: evaluation of a patient/partner intervention model. J Assoc Nurses AIDS Care 2008;19(1):75-84 [FREE Full text] [doi: 10.1016/j.jana.2007.11.002] [Medline: 18191771]

49. Xiao Y, Shao Y, Na Z, Zhao W, Wang R, Fang S, et al. A systematic review and meta-analysis of telephone-based therapy targeting depressive symptoms among low-income people living with HIV. AIDS Behav 2021 Mar;25(2):414-426. [doi: 10.1007/s10461-020-02999-8] [Medline: 32809074]

50. Cheng LJ, Kumar PA, Wong SN, Lau Y. Technology-delivered psychotherapeutic interventions in improving depressive symptoms among people with HIV/AIDS: a systematic review and meta-analysis of randomised controlled trials. AIDS Behav 2020 Jun;24(6):1663-1675. [doi: 10.1007/s10461-019-02691-6] [Medline: 31587115]

51. Molassiotis A, Callaghan P, Twinn SF, Lam SW, Chung WY, Li CK. A pilot study of the effects of cognitive-behavioral group therapy and peer support/counseling in decreasing psychologic distress and improving quality of life in Chinese patients with symptomatic HIV disease. AIDS Patient Care STDS 2002 Feb;16(2):83-96. [doi: 10.1089/10872910252806135] [Medline: $\underline{11874640]}$

52. Zhu M, Cai W, Li L, Guo Y, Monroe-Wise A, Li Y, et al. Mediators of intervention effects on depressive symptoms among people living with HIV: secondary analysis of a mobile health randomized controlled trial using latent growth curve modeling. JMIR Mhealth Uhealth 2019 Nov 15;7(11):e15489 [FREE Full text] [doi: 10.2196/15489] [Medline: 31730042]

53. Li Y, Guo Y, Hong YA, Zhu M, Zeng C, Qiao J, et al. Mechanisms and effects of a WeChat-based intervention on suicide among people living with HIV and depression: path model analysis of a randomized controlled trial. J Med Internet Res 2019 Nov 27;21(11):e14729 [FREE Full text] [doi: 10.2196/14729] [Medline: $\underline{31774411]}$

\section{Abbreviations}

CBSM: cognitive-behavioral stress management

CFI: confirmatory fit index

LGCM: latent growth curve model

mHealth: mobile health

QOL: quality of life

RCT: randomized controlled trial

RMSEA: root mean square error of approximation

SRMR: standardized root mean square residual

TLI: Tucker-Lewis index

WHOQOL-HIV BREF: World Health Organization Quality of Life HIV short version 
Edited by G Eysenbach; submitted 22.11.20; peer-reviewed by JM Simoni, M Ferrer; comments to author 03.06.21; revised version received 05.07.21; accepted 27.12.21; published 17.02 .22

Please cite as:

Zeng Y, Guo Y, Ho RTH, Zhu M, Zeng C, Monroe-Wise A, Li Y, Qiao J, Zhang H, Cai W, Li L, Liu C

Positive Coping as a Mediator of Mobile Health Intervention Effects on Quality of Life Among People Living With HIV: Secondary

Analysis of the Randomized Controlled Trial Run4Love

J Med Internet Res 2022;24(2):e25948

URL: https://www.jmir.org/2022/2/e25948

doi: $\underline{10.2196 / 25948}$

PMID:

(C) Yu Zeng, Yan Guo, Rainbow Tin Hung Ho, Mengting Zhu, Chengbo Zeng, Aliza Monroe-Wise, Yiran Li, Jiaying Qiao, Hanxi Zhang, Weiping Cai, Linghua Li, Cong Liu. Originally published in the Journal of Medical Internet Research (https://www.jmir.org), 17.02.2022. This is an open-access article distributed under the terms of the Creative Commons Attribution License (https://creativecommons.org/licenses/by/4.0/), which permits unrestricted use, distribution, and reproduction in any medium, provided the original work, first published in the Journal of Medical Internet Research, is properly cited. The complete bibliographic information, a link to the original publication on https://www.jmir.org/, as well as this copyright and license information must be included. 